\title{
Systematic review of influenza resistance to the neuraminidase inhibitors
}

\author{
Kristian Thorlund ${ }^{1 *}$, Tahany Awad ${ }^{1}$, Guy Boivin ${ }^{2}$ and Lehana Thabane ${ }^{1,3}$
}

\begin{abstract}
Background: Antivirals play a critical role in the prevention and the management of influenza. One class of antivirals, neuraminidase inhibitors (NAls), is effective against all human influenza viruses. Currently there are two NAI drugs which are licensed worldwide: oseltamivir (Tamiflu ${ }^{\mathbb{B}}$ ) and zanamivir (Relenza ${ }^{\mathbb{B}}$ ); and two drugs which have received recent approval in Japan: peramivir and laninamivir. Until recently, the prevalence of antiviral resistance has been relatively low. However, almost all seasonal H1N1 strains that circulated in 2008-09 were resistant to oseltamivir whereas about $1 \%$ of tested 2009 pandemic H1N1 viruses were found to be resistant to oseltamivir. To date, no studies have demonstrated widespread resistance to zanamivir. It seems likely that the literature on antiviral resistance associated with oseltamivir as well as zanamivir is now sufficiently comprehensive to warrant a systematic review.

The primary objectives were to systematically review the literature to determine the incidence of resistance to oseltamivir, zanamivir, and peramivir in different population groups as well as assess the clinical consequences of antiviral resistance.
\end{abstract}

Methods: We searched MEDLINE and EMBASE without language restrictions in September 2010 to identify studies reporting incidence of resistance to oseltamivir, zanamivir, and peramivir. We used forest plots and meta-analysis of incidence of antiviral resistance associated with the three NAls. Subgroup analyses were done across a number of population groups. Meta-analysis was also performed to evaluate associations between antiviral resistance and clinical complications and symptoms.

Results: We identified 19 studies reporting incidence of antiviral resistance. Meta-analysis of 15 studies yielded a pooled incidence rate for oseltamivir resistance of $2.6 \%(95 \% \mathrm{Cl} 0.7 \%$ to $5.5 \%)$. The incidence rate for all zanamivir resistance studies was $0 \%$. Only one study measured incidence of antiviral resistance among subjects given peramivir and was reported to be $0 \%$. Subgroup analyses detected higher incidence rates among influenza A patients, especially for H1N1 subtype influenza. Considerable heterogeneity between studies precluded definite inferences about subgroup results for immunocompromised patients, in-patients, and children. A meta-analysis of 4 studies reporting association between oseltamivir-resistance and pneumonia yielded a statistically significant risk ratio of 4.2 ( $95 \% \mathrm{Cl} 1.3$ to $13.1, \mathrm{p}=0.02)$. Oseltamivir-resistance was not statistically significantly associated with other clinical complications and symptoms.

Conclusion: Our results demonstrate that that a substantial number of patients may become oseltamivir-resistant as a result of oseltamivir use, and that oseltamivir resistance may be significantly associated with pneumonia. In contrast, zanamivir resistance has been rarely reported to date.

\footnotetext{
* Correspondence: thorluk@mcmaster.ca

'Department of Clinical Epidemiology and Biostatistics, Faculty of Health

Sciences, McMaster University, Hamilton, L8N $3 Z 5$ Ontario, Canada

Full list of author information is available at the end of the article
}

\section{Biomed Central}

(c) 2011 Thorlund et al; licensee BioMed Central Ltd. This is an Open Access article distributed under the terms of the Creative Commons Attribution License (http://creativecommons.org/licenses/by/2.0), which permits unrestricted use, distribution, and reproduction in any medium, provided the original work is properly cited. 


\section{Background}

\section{Description of the Condition}

Influenza (the flu) is an acute infection of the upper respiratory tract which is transmitted via respiratory droplets and direct contact. Immunocompromised people and those with underlying cardio-pulmonary conditions are considered at increased risk from serious influenza-related complications. Annually, influenza infection results in more than 500, 000 deaths worldwide [1]. The influenza virus is an RNA virus that belongs to the Orthomyxoviridae family [2]. There are two main types of influenza virus: type $A$ and type $B$ [2]. These two types are responsible for seasonal flu epidemics each year. The influenza virus is continually evolving and under immune pressure; it may either evolve through small gradual changes in the virus (antigenic drift) or through abrupt major changes in the virus (antigenic shift) most frequently by genetic reassortments [3]. Such changes can result in the emergence of new influenza viruses that can cause pandemics (e.g., the 1918 Spanish flu pandemic and the 2009 H1N1 pandemic)[4].

\section{Description of the interventions}

Vaccines play a critical role in the prevention of influenza [5]. Nevertheless, the efficacy of this intervention could be significantly reduced owing to a mismatch between the seasonal influenza vaccine and the circulating influenza virus and the inability of the host to mount a proper immune response [6]. Therefore, antivirals also play an important role in the prevention and management of influenza. There are two classes of antiviral agents for influenza: adamantanes and neuraminidase inhibitors. Adamantanes (amantadine and rimantadine), however, are not recommended alone for the treatment of influenza due to their lack of activity against influenza $B$ and the high level of influenza A resistance [6,7]. Neuraminidase inhibitors (NAIs) are effective against all human, avian and animal influenza viruses [6-8]. NAIs inhibit the release of virions by competitively inhibiting viral NA, which is a key glycoprotein at the surface of the virus. Currently there are two NAIs drugs which have been approved worldwide: Oseltamivir (Tamiflu ${ }^{\circledR}$ ) and Zanamivir (Relenza ${ }^{\circledR}$ ). Both drugs are approved for treatment of acute uncomplicated illness due to influenza A and B, and are also approved for preventive use [9]. Oseltamivir is provided orally to persons older than one year who have been symptomatic for no more than 2 days [9]. Zanamivir is provided as a dry powder which is given by inhalation in persons aged 7 years and older who have been symptomatic for no more than 2 days [9].

Peramivir is an intravenous neuraminidase inhibitor under development for the treatment of influenza. In
October 2009, the FDA issued an Emergency Use Authorization (EUA) for the use of peramivir based on safety data from Phase 1, Phase 2 trials, and limited Phase 3 trial data. The EUA for peramivir expired in June 2010. However, peramivir has been approved in Japan and Korea. More recently, laninamivir, a long-lasting inhaled neuraminidase inhibitor has also been licensed in Japan $[10,11]$.

\section{Antiviral resistance}

Influenza A and B strains had remained susceptible to oseltamivir with rare exceptions since their availability in 1999. Recent reviews and expert opinions have identified studies reporting prevalence and incidence rates of antiviral resistance among patients treated with oseltamivir [6,7]. Until recently, the prevalence of antiviral resistance had been relatively low $[12,13]$. However, in the influenza season 2008-2009, the Centers for Disease Control and Prevention (CDC) reported a worldwide significant increase in the prevalence of oseltamivir resistance to influenza $\mathrm{A} / \mathrm{H} 1 \mathrm{~N} 1$ viruses (A/Brisbane/59/ 2007-like strains) due to the H275Y NA mutation [9]. Furthermore, about 1\% of tested 2009 pandemic H1N1 viruses (A/California/07/2009 (H1N1) - like strain) were found to be resistant to oseltamivir due to the same mutation. Finally, a Japanese study published in 2004 reported incidence of antiviral resistance in hospitalized children as high as $18 \%[14]$.

To date influenza A and B, including all types of A/ H1N1 virus, remain susceptible to zanamivir. Further, a recent review only found one documented case of zanamivir resistance $[6,15]$. Oseltamivir is easier to administer and has therefore been used vastly more than zanamivir. For this reason, most literature on antiviral resistance associated with NAIs has only investigated antiviral resistance associated with oseltamivir. However, owing to the higher resistance rates associated with oseltamivir, especially for A/H1N1 strains between 2007-09, zanamivir has been increasingly utilized for the treatment and prevention of influenza [9]. Therefore, there is a need to investigate the development of influenza resistance to zanamivir in this time period. Studies investigating resistance to peramivir may also have emerged.

We therefore conducted a systematic review using comprehensive literature search strategies to identify and systematically assess all relevant studies on antiviral resistance associated with oseltamivir, zanamivir, and peramivir.

\section{Objectives}

\section{Primary objective}

Our primary objective was to systematically review the literature to determine the incidence of resistance to oseltamivir, zanamivir, and peramivir in adult 
immunocompetent outpatients for the prevention and treatment of influenza. We did not consider lananimivir since it was not licensed at the time we commenced this review.

\section{Secondary objectives}

Our secondary objectives were to

1) Systematically review data from the literature to determine the incidence of resistance to oseltamivir, zanamivir, and peramivir in different patient populations (e.g., hospitalized, immunocompromised, children, and others).

2) Assess the clinical consequences of antiviral resistance (clinical complications and symptoms associated with antiviral resistance, and severity of complications and symptoms among resistant patients).

\section{Methods}

\section{Criteria for considering studies for this review}

\section{Types of studies}

We included randomized clinical trials (RCTs), cohort and case-control studies, and case reports.

\section{Types of patients}

We included adult immunocompetent outpatients for our primary objective. For our secondary objective we included patients if they were children, immunocompromised, or hospitalized.

\section{Types of interventions}

We included studies that reported incidence of antiviral resistance associated with one or more of the three NAIs oseltamivir, zanamivir, and peramivir. We included all studies regardless of the dose and length of follow-up. We did not include studies where an NAI was administered in combination with another antiviral (e.g., rimantadine)

\section{Types of outcomes}

Our primary and first secondary outcome of interest was incidence of antiviral resistance and our secondary outcomes of interest were the clinical consequences associated with antiviral resistance.

Viral resistance is detected either by the presence of resistance-associated mutations such as the H274Y (N2 numbering) or $\mathrm{H} 275 \mathrm{Y}$ (N1 numbering) substitution or by measuring the median $50 \%$ inhibitory concentration $\left(\mathrm{IC}_{50}\right)$. Commonly used laboratory criteria for determining known antiviral resistance is a substantially elevated $\mathrm{IC}_{50}$ value by enzyme inhibition assay (a value greater than 10-fold that of the corresponding parent virus or greater than three standard deviation (SD) compared to the mean value $[13,16]$. For example, for the H1N1 virus with the most frequent $\mathrm{H} 275 \mathrm{Y}$ NA mutation, the observed IC50 values are usually 200- 400 fold higher than the mean IC50 value [17-21]. However, the definition of antiviral resistance is not standardized and could differ for each of the three NAIs, and may also vary across included studies (due to pre-specification of a threshold or different assays). For that reason, we used the definition of resistance as outlined in the studies to determine the incidence of antiviral resistance.

Measured influenza outcomes included duration of antiviral shedding, the peak viral titers, and the days to resolution of influenza symptoms. For studies reporting on clinical consequences of antiviral resistance, we reported all influenza related complications and symptoms.

\section{Electronic searches and data retrieval}

We searched MEDLINE and EMBASE without language restrictions in September 2010. We limited the search strategy to human studies. We also manually searched reference lists from recent review articles.

\section{Study selection and Data Extraction}

Two reviewers (KT and TA) independently reviewed the abstracts for potential eligibility and subsequently full text publications for eligibility. Disagreements were resolved by discussion.

We extracted a number of variables on study design and methodological characteristics, patient and intervention characteristics, and outcomes from all eligible studies (see appendix). Data extraction was done independently by two reviewers (KT and TA) and disagreements were resolved by discussion.

\section{Methodological Quality Assessment}

For the RCTs, we assessed the adequacy of the methods used for randomization, allocation concealment, blinding, and follow-up [22,23]. We scored the quality for each RCT by assigning one point for each adequate item. With this scale, RCTs can score a minimum of 0 points and a maximum score 4 points. We considered RCTs that scored at least 3 points as high quality. We used the Newcastle-Ottawa Scale (NOS) to assess the adequacy of the employed methodology in the retrieved observational studies [24]. For observational studies reporting incidence of antiviral resistance, there were no control groups. We therefore used a modified version of the NOS scale for cohort studies, taking out the three items that dealt with adequacy of controls or comparison between exposed and non-exposed individuals. With this scale, incidence studies can score a minimum of 0 points and a maximum of 6 points. We considered studies that scored at least 5 points as high quality. For observational studies reporting on consequences of antiviral resistance, we used the complete NOS scale. With this scale, incidence studies can score a minimum of 0 
points and a maximum of 9 points. We considered studies that scored at least 7 points as high quality.

\section{Statistical analysis and reporting of results}

We calculated the antiviral resistance incidence rate and the associated 95\% confidence interval (CI) for all studies and study subgroups. Antiviral resistance incidence rate was calculated as the proportion of patients who developed resistance. We calculated the $95 \% \mathrm{CI}$ based on the assumption that the incidence rate followed a binomial distribution. For incidence rates equal to $0 \%$, we used the "rule of threes" to calculate the upper 95\% CI upper bound [25]. This rule says that the 95\% CI upper bound is equal to $3 / n$, where $n$ is the sample size.

\section{Primary objective - estimating incidence}

We calculated the antiviral resistance incidence rate and the associated 95\% CI for all studies (and subgroups) involving immunocompetent adult out-patients. We produced forest plots and pooled incidence rates across studies using the arcsine method [26].

\section{Secondary objective - incidence across subgroups}

We first performed subgroup analysis on type of NAIs (oseltamivir, zanamivir, or peramivir) and pooled incidence rates within each subgroup using the arcsine method [26]. For each type of NAIs, we then performed subgroup analyses for study design, type of influenza, immunocompetent/immunocompromised patients, out patients/hospitalized patients, adults/children, and prophylaxis/treatment and produced corresponding forest plots. We did not produce pooled estimates in these subgroups.

Secondary objective - consequences of antiviral resistance We qualitatively compared the mean, median, minimum, and maximum duration of antiviral shedding, the peak viral titers, and the days to resolution of influenza symptoms reported in the identified incidence studies.

We reported odds ratios and risk ratios for associations between antiviral resistance and clinical complications or symptoms. Whenever possible, these ratios were combined in a random-effects meta-analysis and presented in a forest plot. Adjusted ratios obtained from multivariate models were preferred to crude ratios. If possible, risk ratios were converted to odds ratios.

For resistant patients reported in case reports, we created a qualitative overview (a table) of clinical complications (e.g., pneumonia) and symptoms which authors believed could be associated with resistance.

\section{Results}

Our search resulted in 1289 hits after removal of duplicate citations. Figure 1 presents the PRISMA diagram

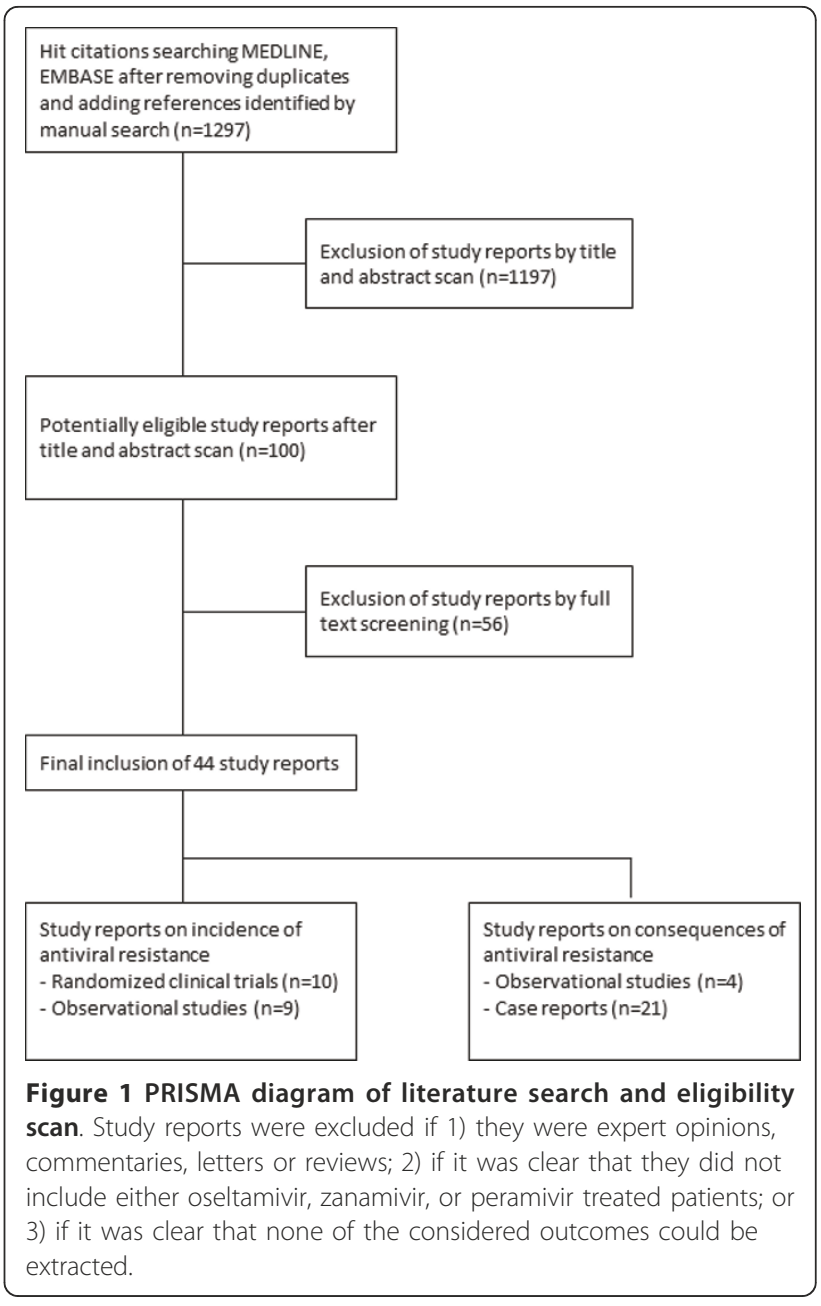

for our eligibility scan. A total of 43 study reports were eligible. Among these, ten were randomized clinical trials (RCTs) that reported incidence of antiviral resistance,[27-36] (effectively fourteen since two publications reported results from four and three RCTs respectively) and nine were cohort studies that reported incidence of antiviral resistance [14,37-44]. Four were case-control studies that reported associations between antiviral resistance and clinical symptoms or complications [45-48]. Lastly, 21 were case reports comprising reports on a total of 27 patients [15,49-68]. None of the ten RCTs or the nine cohort studies made head to head comparisons between any two of the three NAIs (i.e., all 19 studies only included one NAI arm). Thirteen studies measured incidence of antiviral resistance among subjects given oseltamivir,[14,31,33,35,37-44], five studies measured incidence of antiviral resistance among subjects given zanamivir,[27,29,30,32,34] and only one study measured incidence of antiviral resistance among subjects given peramivir [28]. Four oseltamivir studies and all zanamivir and peramivir studies were RCTs. The 
four association studies all estimated associations between oseltamivir resistance and clinical complications and symptoms. Among the 21 case reports, 17 reported on resistance to oseltamivir only, and 2 on resistance to zanamivir only, and 2 on resistance to both. In 12 of the 21 case reports (13 out of 27 patients) where oseltamivir was the initial treatment, patients were eventually switched to zanamivir.

Most studies that reported incidence of antiviral resistance included a mix of our pre-specified subgroups. The methodological quality, the patient characteristics, and the intervention characteristics of the incidence studies are presented in table 1. All RCTs were of high quality. Only one incidence study was low quality according to the modified NOS. The four case-control studies that reported associations between antiviral resistance and clinical symptoms and complications all scored between $7 / 9$ and $9 / 9$ on the NOS.

\section{Primary objective - estimating incidence}

Most studies included a mix of the considered subgroups but did report results separately for each subgroup. It was therefore only possible to extract data from five studies for our primary objective: incidence of resistance among adult immunocompetent out-patients [27-31]. Among these five studies, one reported incidence of antiviral resistance associated with oseltamivir, three reported incidences of antiviral resistance associated with zanamivir, and one reported incidences of antiviral resistance associated with peramivir. In all five studies, patient recruitment ended in or before year 2000. Incidence of resistance was $0 \%$ in all five studies [27-31]. For this reason we did not produce a forest plot.

\section{Secondary objective - incidence across subgroups}

Figure 2 shows the incidence of antiviral resistance subgrouped by NAI (oseltamivir, zanamivir, and peramivir). The pooled incidence rate for oseltamivir was $2.6 \%$ (95\% CI $0.7 \%$ to $5.5 \%$ ). However, the estimated heterogeneity was $\mathrm{I}^{2}=90 \%$. The incidence rate for all zanamivir studies was $0 \%$. All zanamivir studies were RCTs. Further, all zanamivir studies ended in or before year 2000. Only one study measured incidence of antiviral resistance among subjects given peramivir and was reported to be $0 \%$.

Because antiviral resistance was only observed in oseltamivir studies, we did not produce subgroup forest plots including zanamivir or peramivir studies. Figure 3 presents the forest plot of incidence of antiviral resistance to oseltamivir subgrouped by influenza type. The remaining subgroup forest plots of incidence of antiviral resistance are presented in additional files $1,2,3,4$ and 5 (figures A.1 to A.5).
Antiviral resistance was observed among A/H1N1 patients in 5 of 6 studies with incidence rates varying from $3.6 \%$ and $27.3 \%$. Among influenza A/H3N2 patients, incidence rates across three studies were $0 \%$, $3.3 \%, 18 \%$. Incidence rates among influenza B patients were $0 \%$ in two studies and $2 \%$ in one study (see figure 3). Antiviral resistance rates in prophylaxis studies were either $0 \%$ or low (4\%), whereas more than half of the treatment studies reported resistance rates above 5\% (see additional file 1, figure A.1).

Our subgroup analyses on RCTs versus observational studies, immunocompetent versus immunocompromised, out-patients versus in-patients, and adults versus children did not yield any apparent differences between subgroups. The lack of apparent differences was, in part, due to the large degree of heterogeneity within subgroups. All remaining subgroup analyses are presented in the appendices (see additional files 2, 3, 4 and 5 (figures A.2-A.5)).

Secondary objective - consequences of antiviral resistance Figure 4 shows the forest plot of risk ratios for association between oseltamivir resistance and clinical complications that were reported in more than one study. The meta-analysis of the association between oseltamivirresistance and pneumonia yielded a statistically significant risk ratio (RR 4.16, 95\% CI 1.28 to $13.1, \mathrm{p}=0.02$ ). The meta-analyses of the association with otitis yielded a pooled risk ratio of 0.97 (95\% CI 0.41 to 2.43 ). The meta-analysis of the association with hospitalization yielded a pooled risk ratio of 0.60 (95\% CI 0.24 to 1.48 ). The study by Hauge additionally reported adjusted risk ratios for the associations with sinusitis (RR 1.7, 95\% CI 0.4 to 7.5 ) and with bronchitis (RR $0.8,95 \%$ CI 0.4 to 1.8)[47]. Two deaths were reported in the study by Dharan [48]. However, these two patients died before they were admitted to the hospital. No deaths were reported in the other three identified association studies.

The meta-analyses of associations between oseltamivir resistance and the clinical symptoms (cough, fever, sore throat, myalgia, acute/sudden onset, runny nose and headache), did not reveal any differences between oseltamivir-resistant and oseltamivir-susceptible patients. All pooled risk ratio estimates were equal or very close to 1.00 and all 95\% CIs included 1.00. The forest plots for these meta-analyses are presented in additional file 6 and 7 (figure A.6). One study (Dharan) additionally reported odds ratios on chills and breathing difficulty [48]. Risk ratio estimates for these two symptoms were close to 1.00 and had wide confidence intervals.

Table 2 provides a summary of the duration of illness reported across association and incidence studies. Overall, the oseltamivir-resistant and oseltamivir-susceptible patients seem to require the same number of days to reach resolution of symptoms. 
Table 1 Baseline characteristics of studies reporting on incidence of resistance

\begin{tabular}{|c|c|c|c|c|c|c|c|c|c|}
\hline \multirow[b]{2}{*}{$\begin{array}{l}\text { Study first } \\
\text { author }\end{array}$} & \multirow[b]{2}{*}{$\begin{array}{l}\text { Recruitment } \\
\text { Period }\end{array}$} & \multicolumn{2}{|c|}{ Study } & \multicolumn{3}{|c|}{ Intervention } & \multicolumn{3}{|c|}{ Patients } \\
\hline & & Design* & $\begin{array}{l}\text { Quality } \\
\text { score** }^{* *}\end{array}$ & Purpose & Dose & Duration & Immunostatus & $\begin{array}{l}\ln / \\
\text { Out }\end{array}$ & $\begin{array}{l}\text { Age } \\
\text { group }\end{array}$ \\
\hline \multicolumn{10}{|c|}{ Zanamivir studies } \\
\hline Boivin $^{31}$ & 1997-1998 & $\mathrm{RCT}$ & High & Treatment & $10 \mathrm{mg} \mathrm{td}$ & 5 days & Competent & Out & Unclear \\
\hline Hedrick ${ }^{36}$ & 1998-1999 & $\mathrm{RCT}$ & High & Treatment & $10 \mathrm{mg} \mathrm{td}$ & 5 days & Competent & Out & Children \\
\hline Ambrozaitis $^{29}$ & $1997-2000$ & $\mathrm{RCT}$ & High & Prophylactic & $10 \mathrm{mg} \mathrm{td}$ & 14 days & Competent & $\ln$ & Adults \\
\hline Gravenstein $^{32}$ & $1997-2000$ & $\mathrm{RCT}$ & High & Prophylactic & $10 \mathrm{mg} t \mathrm{~d}$ & 14 days & Competent & $\ln$ & Adults \\
\hline Hayden $(1)^{34}$ & 1999-2000 & $\mathrm{RCT}$ & High & Prophylactic & $10 \mathrm{mg} \mathrm{td}$ & 10 days & Competent & Out & Adults \\
\hline \multicolumn{10}{|l|}{ Peramivir study } \\
\hline $\operatorname{Barosso}(a)^{30}$ & $1999-2000$ & $\mathrm{RCT}$ & High & Treatment & $\begin{array}{c}100,200 \text {, or } 400 \mathrm{mg} \mathrm{qd} \text {, or } 200 \mathrm{md} \\
\mathrm{q} 12 \mathrm{~h}\end{array}$ & 5 days & Competent & Out & Adults \\
\hline Barosso $(b)^{30}$ & 1999-2000 & $\mathrm{RCT}$ & High & Treatment & $\begin{array}{c}800 \mathrm{mg} \text { qd(day } 1) \text { then } 400 \mathrm{mg} \text { q2 } 24 \\
\text { or } 400 \mathrm{mg} \text { q24 }\end{array}$ & 5 days & Competent & Out & Adults \\
\hline Barosso $(c)^{30}$ & 1999-2000 & $\mathrm{RCT}$ & High & Treatment & 50,200, or $400 \mathrm{mg} \mathrm{qd}$ & 5 days & Competent & Out & Adults \\
\hline $\operatorname{Barosso}(d)^{30}$ & 1999-2000 & $\mathrm{RCT}$ & High & Treatment & 200,400 or 800 mg & 5 days & Competent & Out & Adults \\
\hline \multicolumn{10}{|c|}{ Oseltamivir studies } \\
\hline Whitley $^{38}$ & 1998-1999 & $\mathrm{RCT}$ & High & Treatment & $\begin{array}{l}2 \text { mg/kg twice daily (max } 100 \text { mg/ } \\
\text { day) }\end{array}$ & 5 days & Competent & Out & Children \\
\hline Hayden $(2)^{35}$ & $2000-2001$ & RCT & High & Prophylactic & 75 mg once daily & 10 days & Competent & Out & Mix \\
\hline Hayden $(3-a)^{33}$ & 2000 & $\mathrm{RCT}$ & High & Treatment & 75 mg/150 mg once/twice daily & 5 days & Competent & Out & Adult \\
\hline Hayden $(3-b)^{33}$ & 2000 & $\mathrm{RCT}$ & High & Treatment & 75 mg once daily & 5 days & Competent & Out & Adult \\
\hline Hayden $(3-c)^{33}$ & 2000 & RCT & High & Prophylactic & 75 mg once daily & 7 days & Competent & Out & Adult \\
\hline $\operatorname{sson}^{37}$ & Before 2009 & $\mathrm{RCT}$ & High & Prophylactic & $\begin{array}{l}75 \mathrm{mg} \text { orally or suspension once } \\
\text { daily for age }=>13 \text {, weight-based } \\
\text { or suspension for age }<13\end{array}$ & 12 days & Compromised & $\ln$ & Unclear \\
\hline Kiso $^{15}$ & $2002-2003$ & OBS & $6 / 6$ & Treatment & $4 \mathrm{mg} / \mathrm{kg}$ & 2-5 days & Competent & Mix & Children \\
\hline Kawai $^{42}$ & 2003-2004 & OBS & $6 / 6$ & Treatment & $\begin{array}{l}75 \mathrm{mg} \text { twice daily for adults and } \\
\text { children }>35 \mathrm{~kg} \text {, weight-based } \\
\text { twice daily for children }<35 \mathrm{~kg}\end{array}$ & 5 days & Unclear & Out & Mix \\
\hline Hatekayama $^{41}$ & $2004-2005$ & OBS & $5 / 6$ & Treatment & Unclear & Unclear & Mix & Unclear & Children \\
\hline Stephenson ${ }^{43}$ & 2005-2007 & OBS & $6 / 6$ & Treatment & $\begin{array}{c}\text { Twice daily weight-based dosing } \\
\text { regimen }\end{array}$ & 5 days & Competent & Unclear & Mix \\
\hline $\operatorname{Cost}^{39}$ & 2009 & OBS & $4 / 6$ & Prophylactic & Unclear & Unclear & Compromised & $\ln$ & Children \\
\hline Harvala ${ }^{40}$ & 2009 & OBS & $6 / 6$ & Treatment & Unclear & Unclear & Mix & Unclear & Unclear \\
\hline Tramontana ${ }^{44}$ & 2009 & OBS & $6 / 6$ & Treatment & Varied across patients & $\begin{array}{l}\text { Up to } 43 \\
\text { days }\end{array}$ & Compromised & In & Adults \\
\hline Wang $^{45}$ & 2009 & OBS & $6 / 6$ & Treatment & Unclear & Unclear & Mix & $\ln$ & $\operatorname{mix}$ \\
\hline Winzer $^{46}$ & 2009 & OBS & $5 / 6$ & Treatment & Unclear & Unclear & Unclear & Unclear & $\operatorname{mix}$ \\
\hline
\end{tabular}

*Study design is either a randomized clinical trial (RCT) or an observational study (OBS)

${ }^{* *}$ Quality scores for RCTs range from 1 to 4 . Study scores for OBSs range from 1 to 6 . Low scores indicate low quality, high scores indicate high quality.

The identified case reports showed a wide spectrum of complications associated with antiviral resistance. Table 3 summarized these complications in relation to the type of treatment, patient group and influenza. The complications associated with antiviral resistance were typically of a respiratory nature. Prolonged fever was also common. In 9 case reports, oseltamivir resistant patients were switched to zanamivir once viral resistance had been detected. In some cases, patients seemed to recover as a result of the switch, in others cases they did not.

\section{Discussion}

The primary focus of this review was to describe the incidence of resistance to oseltamivir, zanamivir, and peramivir in adult immunocompetent outpatients for the prevention and treatment of influenza. However, we 


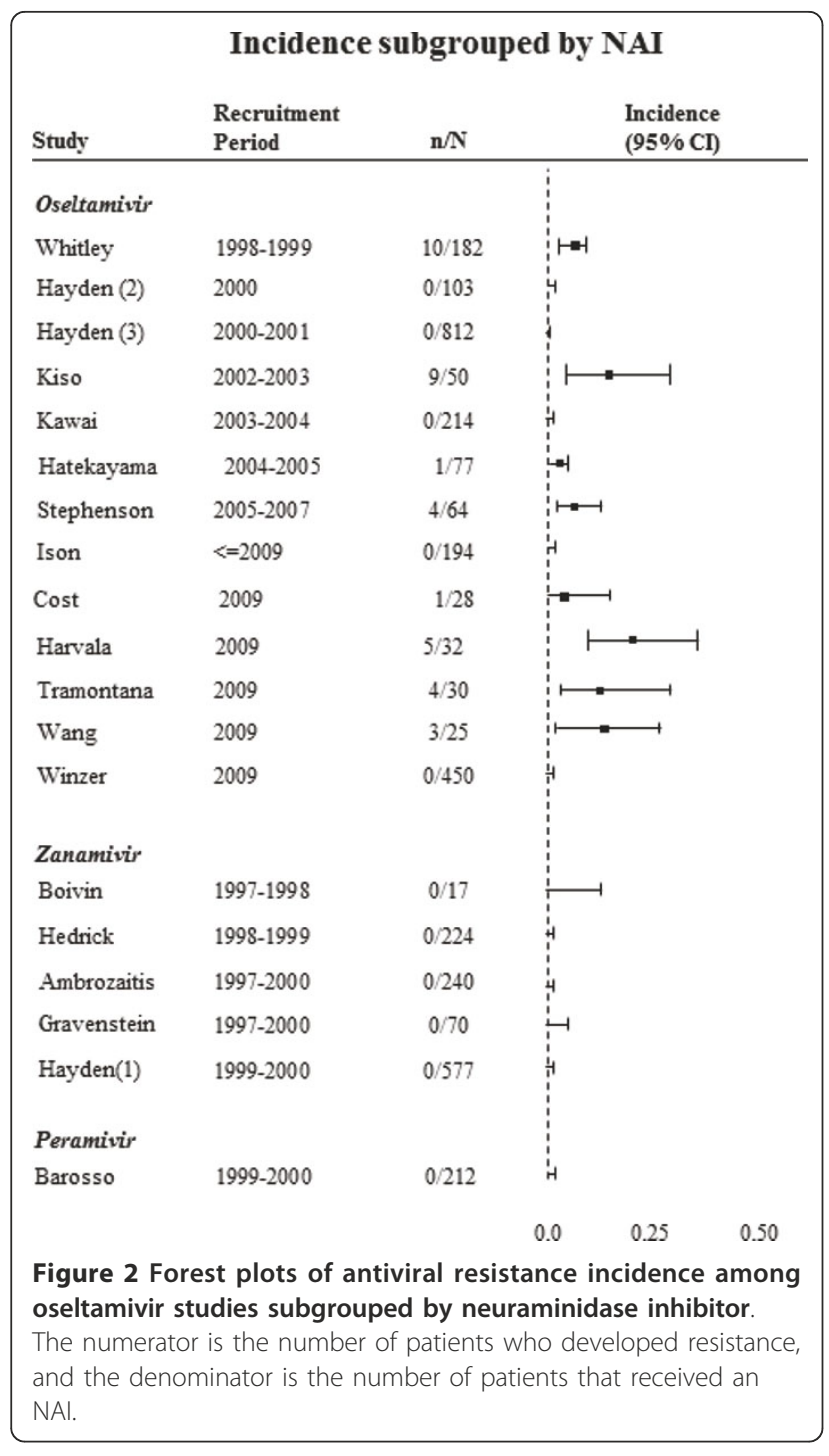

did not identify sufficient evidence to draw any conclusions about this issue. The secondary focus of our review was to describe the incidence and consequences of antiviral resistance across various population groups. Overall the incidence of oseltamivir-resistance across studies was $2 \%$. We found higher oseltamivir-resistance incidence rates among influenza A patients - particularly those of the H1N1 subtype. Zanamivir was associated with $0 \%$ incidence of resistance. Only one study measured incidence of antiviral resistance among subjects given peramivir and it was reported to be $0 \%$. However, zanamivir and peramivir clinical trials stopped enrolling in year 2000 at the latest, and therefore have little generalizability. We did not compare the incidence rates between drugs because there are no head-to-head studies that have compared these drugs. Our analyses of consequences associated with development of antiviral resistance demonstrated that oseltamivir-resistant

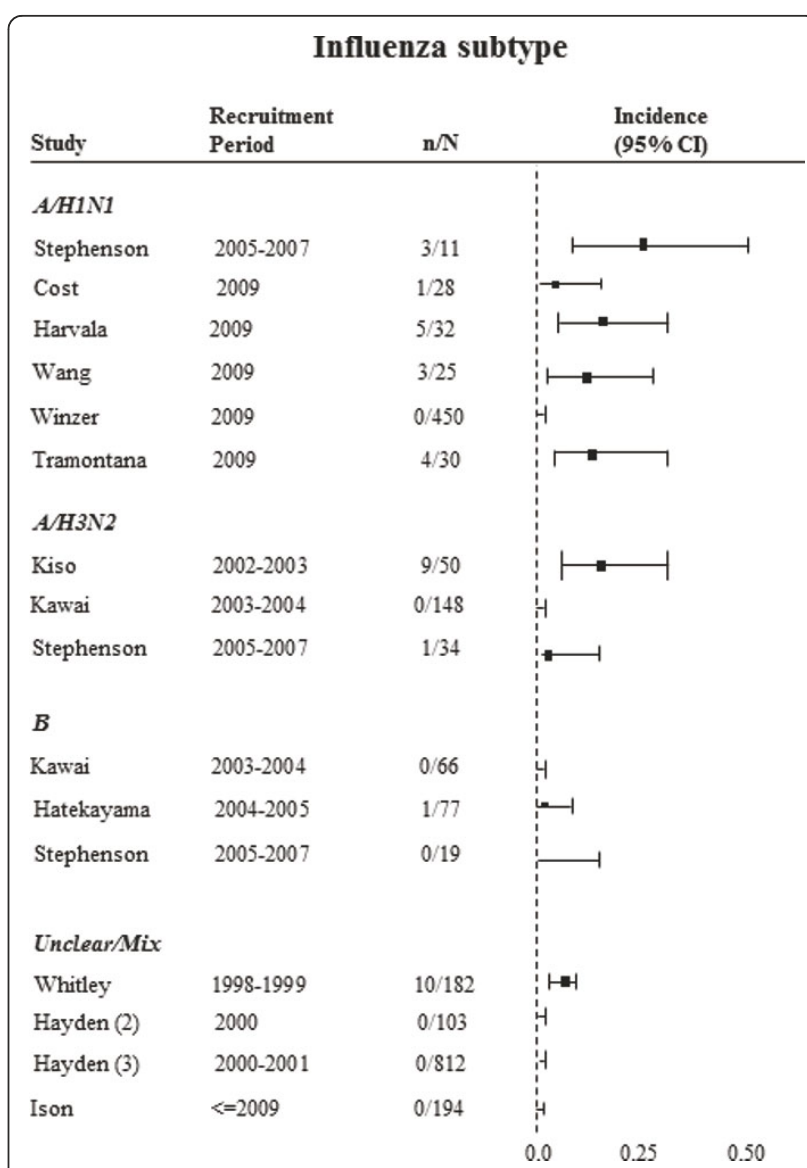

Figure 3 Forest plots of antiviral resistance incidence among oseltamivir studies subgrouped by type of influenza. The numerator is the number of patients who developed resistance, and the denominator is the number of patients that received an NAl.

patients are approximately 4 times more likely to suffer from pneumonia than oseltamivir-susceptible patients. We did not find any associations between oseltamivirresistance and other clinical complications or symptoms. We did not identify any studies reporting on association between zanamivir or peramivir resistance and clinical complications or symptoms. Our review of case reports shows that antiviral resistance can be associated with a number of serious complications. Such complications are typically of a respiratory nature and may in some cases be so severe that the patient will die, but whether it depends on viral resistance or on the host's immune response needs to be determined.

Our review comes with a number of strengths and limitations. We collectively reviewed randomized clinical trials, cohort studies, case series, and case reports. Randomized clinical trials are typically conducted under controlled settings that may not be entirely representative of general clinical practice. In the context of our review, such controlled settings may substantially reduce the risk of developing antiviral resistance. By including 


\section{Associations between oseltamivir-resistance and clinical complications}

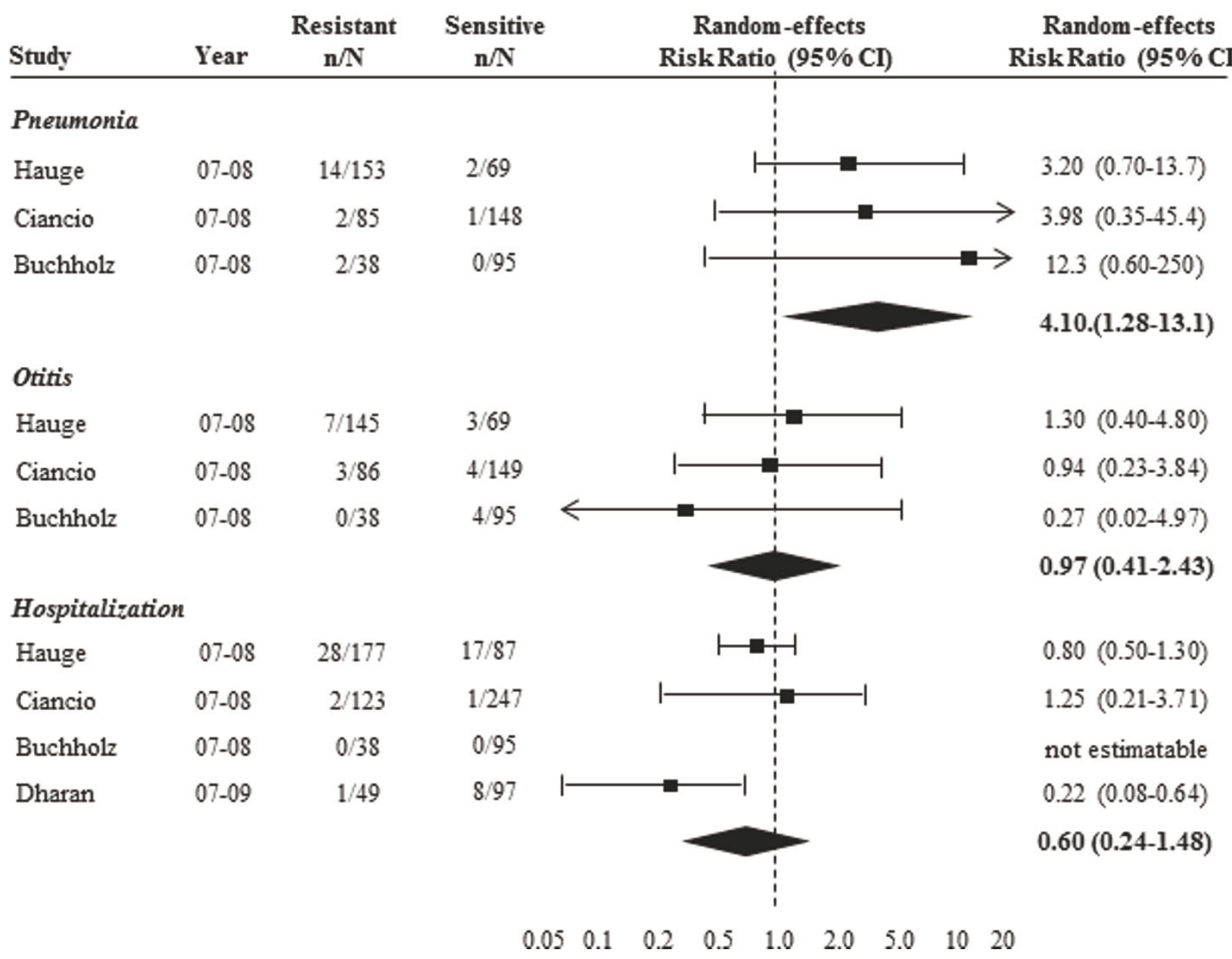

Figure 4 Forest plots of risk ratios for associations between antiviral resistance and clinical complications. The risk ratios from the studies by Hauge and Ciancio are adjusted risk ratios obtained from multivariable models. The risk ratios from the Buchholz study are crude risk ratios based on zero-event continuity correction of 0.5 . The Dharan risk ratio was transformed from an adjusted odds ratio based on a multivariable model.

observational studies in our review, we obtain incidence estimates that are generalizable to conventional clinical practice settings. Furthermore, our additional inclusion of case reports allowed us to evaluate the severity of the clinical complications that can arise from antiviral resistance.

Despite including a wide range of considered study designs, our review finds its limitations in the paucity of evidence. We did not find any recent studies that investigated incidence of antiviral resistance associated with zanamivir or peramivir, in fact, all studies on zanamivir ended patients' recruitment in 2000 at the latest. Thus, we were unable to assess whether zanamivir and peramivir still yields a (close to) $0 \%$ incidence of antiviral resistance. In addition to the time factor, it is reported that there is a cross-resistance association between oseltamivir and peramivir $[49,69]$. For patients infected with $\mathrm{A} / \mathrm{H} 1 \mathrm{~N} 1$ virus harboring the $\mathrm{H} 275 \mathrm{Y}$ mutation, studies conducted before the 2007-2009 seasons are therefore likely to underestimate resistance to peramivir dramatically. Furthermore, recent peramivir clinical trials have evaluated a parenteral injection form instead of prior oral tablets $[28,70]$.

Most oseltamivir studies included a mix of population subgroups and had little or no reporting on subgroup results. As a result, much within-subgroup heterogeneity ensued, and thus, many of our subgroup analyses did not yield any 'apparent' differences. The presence of a mixture of resistant and susceptible viruses especially in immunocompromised hosts may also potentially 
Table 2 Summary of symptoms and days to resolution of symptoms reported across association studies and incidence studies

\begin{tabular}{|c|c|c|c|c|}
\hline \multirow[t]{2}{*}{ Study } & \multicolumn{2}{|r|}{ Resistant patients } & \multicolumn{2}{|r|}{ Sensitive patients } \\
\hline & $\mathrm{n}$ & Reported symptoms and durations & $\mathrm{n}$ & Reported symptoms and durations \\
\hline \multicolumn{5}{|l|}{ Association studies } \\
\hline Buchholz $(2009)^{48}$ & 11 & $\begin{array}{c}\text { Duration of sick leave: } \\
\text { Median: } 7 \text { days } \\
\text { IQR: } 6 \text { to } 14\end{array}$ & 26 & $\begin{array}{c}\text { Duration of sick leave: } \\
\text { Median: } 7 \text { days } \\
\text { IQR: } 7 \text { to } 10\end{array}$ \\
\hline Buchholz $(2009)^{48}$ & 38 & $\begin{array}{c}\text { Days confined to bed: } \\
\text { Median: } 3.5 \text { days } \\
\text { IQR: } 2 \text { to } 7\end{array}$ & 93 & $\begin{array}{l}\text { Days confined to bed: } \\
\text { Median: } 3 \text { days } \\
\text { IQR: } 2 \text { to } 5\end{array}$ \\
\hline Dharan $(2009)^{50}$ & 49 & $\begin{array}{c}\text { Activities limited: } 1-7 \text { days } \\
\text { Median: } 4 \text { days }\end{array}$ & 97 & $\begin{array}{l}\text { Activities limited: } 1-30 \text { days } \\
\text { Median: } 4 \text { days }\end{array}$ \\
\hline Dharan $(2009)^{50}$ & 38 & $\begin{array}{c}\text { Missed work or school: 1-10 days } \\
\text { Median: } 4 \text { days }\end{array}$ & 97 & $\begin{array}{c}\text { Missed work or school: 1-30 days } \\
\text { Median: } 4 \text { days }\end{array}$ \\
\hline \multicolumn{5}{|l|}{ Incidence studies } \\
\hline Kiso $(2004)^{15}$ & 9 & $\begin{array}{l}\text { Duration of fever: } 2-7 \text { days } \\
\text { Median }=3 \text { days }\end{array}$ & 41 & $\begin{array}{l}\text { Duration of fever: } 1-6 \text { days } \\
\text { Median }=3 \text { days }\end{array}$ \\
\hline Hatakeyama $(2007)^{41}$ & 1 & Duration of fever: 2 days & 76 & Mean duration of fever: 2.4 days \\
\hline \multirow[t]{2}{*}{ Stephenson $(2009)^{43}$} & 4 & $\begin{array}{l}\text { Duration of fever: } 5-6 \text { days } \\
\text { Full recovery after: } 9-10 \text { days }\end{array}$ & 60 & Authors commented no difference observec \\
\hline & & & & between resistant and sensitive patients \\
\hline
\end{tabular}

complicate the interpretation of our findings. Lastly, we did not find any studies on incidence of antiviral resistance among $\mathrm{H} 5 \mathrm{~N} 1$ patients, and only two case reports on $\mathrm{H} 5 \mathrm{~N} 1$ patients $[51,52]$. As for case reports, it is likely that our search may have missed a substantial number of case reports due to such publications being poorly indexed in the utilized search engines. We excluded some case reports of oseltamivir resistance in $\mathrm{H} 5 \mathrm{~N} 1$ infected humans because no clinical data was reported [71] or because resistance was detected pre-therapy [72].

The rates at which pneumonia occurred in oseltamivir-susceptible patients were between $1 \%$ and $3 \%$ [45-48]. Meanwhile, our meta-analysis suggests that oseltamivirresistant patients are 4-times more likely to suffer from pneumonia. Assuming that $2 \%$ of oseltamivir-susceptible patients suffer from pneumonia, 1 out of every 50 oseltamivir-susceptible patients would suffer from pneumonia in comparison to 1 out of every 12 oseltamivirresistant patients. It is noteworthy that in the identified case reports, many cases of resistance arose in immunocompromised patients adding a confounder in the interpretation of this association.

Our review provides valuable insight on the incidence of antiviral resistance associated with oseltamivir use. However, we were not able to draw inferences about incidence of antiviral resistance associated with zanamivir or peramivir use due to the absence of recent studies on the topic. The reviewed case reports mainly involved immunocompromised subjects who were hospitalized (in-patients) and received oseltamivir as treatment rather than prophylaxis. This could suggest a tendency that notable complications associated with antiviral resistance more frequently arise among such patients. To confirm this, however, future cohort studies that investigate the associations between antiviral resistance and complications should incorporate patient and treatment characteristics in the multivariate models.

\section{Conclusion}

Our results demonstrate that that a substantial number of patients may become oseltamivir-resistant as a result of oseltamivir use, and that oseltamivir resistance may be significantly associated with pneumonia. In contrast, zanamivir resistance has been rarely reported to date.

\section{Financial Competing interests}

This review was funded by GlaxoSmithKline Inc. (GSK).

Lehana Thabane (LT) has received consultancies from several pharmaceutical companies including GSK, AstraZeneca, CanReg Inc., F. Hoffman La Roche, Theralase Inc, Sorono Canada Inc, Merck Frosst - Schering Pharmaceuticals, Pfizer, Proctor and Gamble Pharmaceuticals, and law firms that include Newton Wong and Associates, and Paterson McDougall.

Guy Boivin (BG) has received research grants and honoraria from GSK and Hoffman La Roche.

Tahany Awad (TA) has received consultancies from Hoffman La Roche.

Kristian Thorlund (KT) has no financial interests to declare.

\section{Non-financial Competing interests}

The authors declare that they have no competing interests. 
Table 3 Summary of patient and treatment characteristics, and complications believed to be associated with antiviral resistance in the reviewed case reports

\begin{tabular}{|c|c|c|c|c|c|c|c|c|c|}
\hline Study & Period & $\begin{array}{l}\text { Flu } \\
\text { type }\end{array}$ & Mutation & $\begin{array}{l}\text { Proph/ } \\
\text { Treat }\end{array}$ & $\begin{array}{l}\text { Competent/ } \\
\text { Compromised }\end{array}$ & $\begin{array}{l}\text { In/Out } \\
\text { Patient }\end{array}$ & Age & $\begin{array}{l}\text { Days to } \\
\text { resistance } \\
\text { detection }\end{array}$ & Complications associated with resistance \\
\hline \multicolumn{10}{|c|}{ Oseltamivir resistance } \\
\hline $\mathrm{Baz}^{52}$ & $\begin{array}{l}2005- \\
2006\end{array}$ & $\mathrm{H} 3 \mathrm{~N} 2$ & $\begin{array}{l}\mathrm{E} 596 \mathrm{G} \\
\mathrm{E} 119 \mathrm{~V} \\
1222 \mathrm{~V} \\
1223 \mathrm{~V}\end{array}$ & Treat & Compromised & In & $4 \mathrm{~m}$ & 14 & $\begin{array}{l}\text { Respiratory complications, prolonged viral } \\
\text { shedding (about } 90 \text { days) }\end{array}$ \\
\hline $\mathrm{Baz}^{52}$ & 2009 & H1N1 & $\mathrm{H} 275 \mathrm{Y}$ & $\begin{array}{l}\text { Postexp } \\
\text { Proph }\end{array}$ & Competent & Out & $59 y$ & 8 & None. Recovered after 2 weeks \\
\hline Campanini $^{55}$ & 2009 & $\mathrm{H} 3 \mathrm{~N} 2$ & $\mathrm{H} 274 \mathrm{Y}$ & Treat & Compromised & $\ln$ & $2 y$ & 18 & 42 days to resolution of flu symptoms \\
\hline Cane $e^{56}$ & 2010 & H1N1 & $\mathrm{H} 275 \mathrm{Y}$ & Treat & Compromised & $\ln$ & $3 y$ & NA & 1 month to resolution of flu symptoms \\
\hline CDC-Weekly $(1)^{57}$ & 2009 & $\mathrm{H} 1 \mathrm{~N} 1$ & $\begin{array}{l}\mathrm{H} 275 \mathrm{Y} \\
\mathrm{I} 223 \mathrm{~V}\end{array}$ & Proph & Competent & Out & Teens & 27 & None ("uneventful recovery") \\
\hline CDC-Weekly $(1)^{57}$ & 2009 & H1N1 & $\begin{array}{l}\mathrm{H} 275 \mathrm{Y} \\
\mathrm{I} 223 \mathrm{~V}\end{array}$ & Proph & Competent & Out & Teens & 14 & None ("uneventful recovery") \\
\hline CDC-Weekly $(2)^{48}$ & 2009 & H1N1 & $\mathrm{H} 275 \mathrm{Y}$ & Treat & Compromised & In & Teens & 30 & 2 months to recovery \\
\hline CDC-Weekly $(2)^{48}$ & 2009 & H1N1 & $\mathrm{H} 275 \mathrm{Y}$ & Treat & Compromised & $\ln$ & $40 y$ & 30 & $\begin{array}{l}2 \text { months to revovery, prolonged neutron- } \\
\text { penia and protracted bone marrow } \\
\text { recovery, neutropenic fever, coagulase- } \\
\text { negative Staphylococcus bacteremia, and } \\
\text { Pneumocystis }\end{array}$ \\
\hline Couturier $(1)^{59}$ & 2009 & $\mathrm{H} 1 \mathrm{~N} 1$ & $\mathrm{H} 275 \mathrm{Y}$ & Treat & Compromised & $\ln$ & $69 y$ & 9 & Renal function declined. Died after 17 days. \\
\hline Couturier $(2)^{59}$ & 2009 & $\mathrm{H} 1 \mathrm{~N} 1$ & $\mathrm{H} 275 \mathrm{Y}$ & Treat & Compromised & $\ln$ & $66 y$ & 21 & $\begin{array}{l}\text { Recovered after } 1 \text { month. Caught fever } \\
\text { again after } 3 \text { months and died. }\end{array}$ \\
\hline Couturier $(3)^{59}$ & 2009 & H1N1 & $\mathrm{H} 275 \mathrm{Y}$ & Proph & Competent & Out & $36 y$ & NA & None \\
\hline De Jong ${ }^{54}$ & 2005 & H5N1 & $\mathrm{H} 274 \mathrm{Y}$ & Treat & Competent & In & $13 y$ & 5 & $\begin{array}{l}\text { Patient died. Suffered from hypoxia and } \\
\text { pneumonia }\end{array}$ \\
\hline Dulek $^{60}$ & 2009 & H1N1 & $\mathrm{H} 275 \mathrm{Y}$ & Treat & Compromised & $\ln$ & $18 \mathrm{~m}$ & 22 & $\begin{array}{l}52 \text { days of viral shedding, progressive } \\
\text { pulmonary disease }\end{array}$ \\
\hline Gaur $^{61}$ & 2009 & H1N1 & $\mathrm{H} 275 \mathrm{Y}$ & Treat & Compromised & In & $10 y$ & 14 & None reported \\
\hline Glikman $^{62}$ & 2009 & $\mathrm{H} 1 \mathrm{~N} 1$ & $\mathrm{H} 275 \mathrm{Y}$ & Treat & Compromised & $\ln$ & $11 y$ & 13 & Prolonged fever (> 21 days) \\
\hline Hill-Cawthorne ${ }^{63}$ & 2009 & $\mathrm{H} 1 \mathrm{~N} 1$ & $\mathrm{H} 275 \mathrm{Y}$ & Treat & Compromised & Out & $56 y$ & 20 & Prolonged fever and cough (2 months) \\
\hline $\operatorname{son}(1)^{64}$ & 2001 & NA & $\begin{array}{l}\text { Asp198Asn } \\
\text { Aer285Ala }\end{array}$ & Proph & Compromised & In & $2 y$ & 42 & $\begin{array}{l}\text { Continued rhinorrhea and dry cough, } \\
\text { progressive respitatory distress, } \\
\text { gastrointestinal bleeding. Eventually died. }\end{array}$ \\
\hline $\operatorname{lson}(2)^{64}$ & 2002 & $\mathrm{H} 3 \mathrm{~N} 2$ & $\begin{array}{l}\text { Arg142Gly } \\
\text { Tyr195Phe }\end{array}$ & Treat & Compromised & $\ln$ & $63 y$ & 90 & Prolonged cough and nasal congestion \\
\hline $\operatorname{son}(3)^{64}$ & 2003 & $\mathrm{H} 3 \mathrm{~N} 2$ & $\begin{array}{l}\text { Glu119Val } \\
\text { Ser31Asn }\end{array}$ & Treat & Compromised & $\ln$ & $60 y$ & NA & $\begin{array}{l}\text { Progressive respiratory compromise and } \\
\text { pneumonia, continued respiratory failure. } \\
\text { Died of haemorrhagic stroke. }\end{array}$ \\
\hline $\mathrm{Le}^{53}$ & 2005 & N5N1 & $\mathrm{H} 274 \mathrm{Y}$ & Both & Competent & Out & $14 y$ & 4 & None. Recovered after 2 weeks. \\
\hline Memoli ${ }^{65}$ & 2009 & $\mathrm{H} 1 \mathrm{~N} 1$ & $\begin{array}{l}\text { Amino- } \\
\text { acid } \\
\text { position } \\
245-248\end{array}$ & Treat & Compromised & $\ln$ & $43 y$ & 5 & None. Recovered after 2 weeks. \\
\hline \multirow[t]{2}{*}{ Nguyen**66 } & 2009 & H1N1 & $\mathrm{H} 27 \mathrm{Y}$ & Treat & Compromised & $\ln$ & $14 y$ & 17 & Died of complications after 2 months \\
\hline & & & I223R & & & & & & \\
\hline Rousset**67 $^{*}$ & 2009 & $\mathrm{H} 1 \mathrm{~N} 1$ & $\mathrm{H} 275 \mathrm{Y}$ & Treat & Compromised & $\ln$ & $24 y$ & 6 & Patient died at day 140 \\
\hline Speers $^{68}$ & 2009 & H1N1 & $\mathrm{H} 275 \mathrm{Y}$ & Treat & Compromised & $\ln$ & $38 y$ & 3 & None. Eventually died \\
\hline Thabet ${ }^{69}$ & 2009 & H1N1 & $\mathrm{H} 274 \mathrm{Y}$ & Treat & Compromised & $\ln$ & $3 y$ & 10 & None reported. \\
\hline Van der Vries*70 & 2009 & $\mathrm{H} 1 \mathrm{~N} 1$ & $\mathrm{H} 275 \mathrm{Y}$ & Treat & Compromised & $\ln$ & $5 y$ & 7 & Resolutions of symptoms after 3 months \\
\hline \multicolumn{10}{|c|}{ Zanamivir resistance } \\
\hline Gubareva $^{16}$ & 1998 & NA & $\begin{array}{l}\text { 152Argr- } \\
\text { Lys }\end{array}$ & Treat & Compromised & $\ln$ & $18 \mathrm{~m}$ & 8 & Not resolved, patients died. \\
\hline Van der Vries ${ }^{* 70}$ & 2009 & H1N1 & I223R & Treat & Compromised & In & $5 y$ & 56 & Resolutions of symptoms after 3 months \\
\hline
\end{tabular}

* patient was treated with oseltamivir first, zanamivir second, and developed resistance to both antivirals

** patient also had reduced sensitivity to zanamivir 


\section{Additional material}

Additional file 1: Additional figure 1 (Figure A.1). Forest plots of antiviral resistance incidence among oseltamivir studies subgrouped by study design. The numerator is the number of patients who developed resistance, and the denominator is the number of patients that received an NAl.

Additional file 2: Additional figure 2 (Figure A.2). Forest plots of antiviral resistance incidence among oseltamivir studies subgrouped by immunocompetent and immunocompromised patients. The numerator is the number of patients who developed resistance, and the denominator is the number of patients that received an NAl.

Additional file 3: Additional figure 3 (Figure A.3). Forest plots of antiviral resistance incidence among oseltamivir studies subgrouped by out-patients and in-patients. The numerator is the number of patients who developed resistance, and the denominator is the number of patients that received an NAl.

Additional file 4: Additional figure 4 (Figure A.4). Forest plots of antiviral resistance incidence among oseltamivir studies subgrouped by study age group (adults or children). The numerator is the number of patients who developed resistance, and the denominator is the number of patients that received an NAl.

Additional file 5: Additional figure 5 (Figure A.5). Forest plots of antiviral resistance incidence among oseltamivir studies subgrouped by intervention purpose. The numerator is the number of patients who developed resistance, and the denominator is the number of patients that received an NAl.

Additional file 6: Additional figure 6 (Figure A.6). Forest plots of risk ratios for associations between antiviral resistance and clinical symptoms. All risk ratio estimates are crude estimates

Additional file 7: Additional figure 6 (Figure A.6). Forest plots of risk ratios for associations between antiviral resistance and clinical symptoms. All risk ratio estimates are crude estimates

\section{Acknowledgements}

We would like to acknowledge Andrea McLellan for preparing the MEDLINE and EMBASE search strategy.

\section{Author details}

'Department of Clinical Epidemiology and Biostatistics, Faculty of Health Sciences, McMaster University, Hamilton, L8N $3 Z 5$ Ontario, Canada. ${ }^{2}$ Centre de recherche en infectiologie, CHUQ-CHUL, 2705 boul. Laurier, Québec (Québec), Canada, GIV 4G2, Canada. ${ }^{3}$ Biostatistics Unit, Father Sean O'Sullivan Research Centre, St Joseph's Healthcare - Hamilton, Hamilton L8N 4A6 Ontario, Canada.

\section{Authors' contributions}

$K T$ drafted the protocol and the manuscript, assessed eligibility of identified study abstracts, extracted data, scored the quality of all eligible studies and performed all statistical analyses. TA contributed to the writing of the protocol and the manuscript, contributed to the design of the review, contributed to the interpretation of data, assessed eligibility of identified study abstracts, extracted data and scored the quality of all eligible studies. GB and LT contributed the writing of the protocol and manuscript, contributed to the design of the review and contributed to the interpretation of data.

All authors read and approved the final version of the manuscript.

Received: 28 January 2011 Accepted: 19 May 2011

Published: 19 May 2011

\section{References}

1. Influenza infection. 2010 [http://www.who.int/mediacentre/factsheets/ fs211/en/index.html].

2. Influenza: Pathogens and disease. 2010 [http://www.who.int/biologicals/ areas/vaccines/influenza/influenza_pathogens_disease/en/index.html].
3. Influenza viruses. 2010 [http://www.cdc.gov/flu/avian/gen-info/flu-viruses $\mathrm{htm}]$.

4. CDC Resources for Pandemic Flu. 2010 [http://www.cdc.gov/flu/ pandemic].

5. ACIP Recommendations: Introduction and Biology of Influenza. 2010 [http://www.cdc.gov/flu/professionals/acip/background.htm].

6. Hurt $\mathrm{AC}, \mathrm{HO} H \mathrm{HT}$, Barr I: Resistance to anti-influenza drugs: adamantanes and neuraminidase inhibitors. Expert Rev Anti Infect Ther 2006, 4:795-805.

7. Schirmer $\mathrm{P}$, Holodniy M: Oseltamivir for treatment and prophylaxis of influenza infection. Expert Opin Drug Saf 2009, 8:357-371.

8. Jefferson T, Jones MA, Doshi P, Del Mar CB, Dooley L, Foxlee R: Neuraminidase inhibitors for preventing and treating influenza in health adults. Cochrane Database of Systematic Reviews 2010, 2.

9. Updated interim recommendations for the use of antiviral medications in the treatment and prevention of influenza for the 2009-2010 season. 2010 [http://www.cdc.gov/H1N1flu/recommendations.htm].

10. Kubo S, Tomozawa T, Kubata M, Tokumitau A, Yamashita M: Laninamivir prodrug CS-8958, a long-acting neuraminidase inhibitor, shows superior anti-influenza virus activity after a single administration. Antimicrob Agents Chemother 2010, 54:1256-1264.

11. Yamashita M: Laninamivir and its prodrug, CS-8958: long-acting neuraminidase inhibitors for the treatment of influenza. Antimicrob Agents Chemother 2011, 21:71-84.

12. Hurt AC, Barr IG: Influenza viruses with reduced sensitivity to the NA inhibitor drugs in untreated young children. Communicable Diseases Intelligence 2008, 32:57-62.

13. Monto AS, McKimm-Breschken JL, Macken C, Hampson AW, Hay A, Klimov A, Tashiro M, Webster RG, Aymard M, Hayden FG, et al: Detection of influenza viruses resistant to neuraminidase inhibitors in global surveillance during the first 3 years of their use. Pediatric Infectious Diseases Journal 2006, 27:S110-S112

14. Kiso M, Mitamura K, Sakai-Tagawa Y, Shiraishi K, Kawakami C, Kimura K, Hayden FG, Sugaya N, Kawaoka Y: Resistant influenza A viruses in children treated with oseltamivir: descriptive study. Lancet 2004, 364:759-765

15. Gubareva LV, Matrosovich MN, Brenner MK, Bethell RC, Webster RG Evidence for zanamivir resistance in an immunocompromised child infected with influenza B virus. Journal of Infectious Diseases 1998, 178:1257-1262

16. Meijer A, Lackenby A, Hungnes O, Lina B, van der Werf S, Schweger B, Opp M, Paget J, van de Kassteele J, Hay A, et al: Oseltamivir-resistant influenza virus A (H1N1), Europe 2007-08 Season. Emerging Infectious Diseases 2009, 15:552-560.

17. Abed $Y$, Goyette N, Boivin G: A reverse genetics study of resistance to neuraminidase inhibitors in an in?uenzaA(H1N1) virus. Antiviral Therapy 2004, 9:577-581.

18. Aoki FY, Boivin G, Roberts N: Influenza virus susceptibility and resistance to oseltamivir. Antiviral Therapy 2007, 12:603-616.

19. Collins PJ, Haire LF, Lin YP, Liu J, Russel RJ, Walker PA, et al: Crystal structures of oseltamivir-resistant in?uenza virus neuraminidase mutants. Nature 2011, 453:1258-1261.

20. Lackenby A, Hughes C, Dudman S, Meijer A, Pareek M, Hay A: Emergence of resistance to oseltamivir among influenza $A(\mathrm{H} 1 \mathrm{~N} 1)$ viruses in Europe. Eurosurveillance 2008, 13:1-2.

21. Wang MZ, Tai CV, Mendel DB: Mechanism by which mutations at His 274 alter sensitivity of in?uenza A virus N1 neuraminidase to oseltamivir carboxylate and zanamivir. Antimicrob Agents Chemother 2002, 46:3809-3816.

22. Higgins JP, Green S: Cochrane Handbook for systematic reviews of interventions, version 5.0.0. John Wiley \& Sons; 2009.

23. Wood L, Egger M, Gluud LL, Schulz K, Jüni P, Gluud C, Martin R, Wood A, Sterne JA: Empirical evidence of bias in treatment effect estimates in controlled trials with different interventions and outcomes: metaepidemioogical study. British Medical Journal 2008, 336:601-605.

24. Wells GA, Shea B, O'Connell D, Peterson J, Welch V, Losos M, Tugwell P: The Newcastle-Ottawa Scale (NOS) for assessing the quality of nonrandomized studies in meta-analysis. 2010 [http://www.ohri.ca/programs/ clinical_epidemiology/oxford.htm].

25. Belle G: Statistical rules of thumb. New York: John Wiley \& Sons; 2002.

26. Rucker $G$, Schwarzer $G$, Carpenter J, Olkin I: Why add anything to nothing? The arcsine difference as a measure of treatment effect in meta-analysis with zero cells. Statistics in Medicine 2009, 28:721-738. 
27. Ambrozaitis A, Gravenstein S, van Essen GA, Rubinstein E, Balciuniene L, Stikleryte A, Crawford C, Elliott M, Shult P: Inhaled zanamivir versus placebo for the prevention of influenza outbreaks in an unvaccinated long-term care population. Journal of the American Medical Directors Association 2005, 6:367-374.

28. Barosso L, Treanor J, Gubareva L, Hayden FG: Efficacy and tolerability of the oral neuraminidase inhibitor peramivir in experimental human influenza: randomized, controlled trials for prophylaxis and treatment. Antiviral Therapy 2005, 10:901-910.

29. Boivin G, Goyette N, Hardy I, Aoki F, Wagner A, Trottier S: Rapid Antiviral Effect of Inhaled Zanamivir in the Treatment of Naturally OccurringInfluenza in Otherwise Healthy Adults. The Journal of Infectious Diseases 2000, 181:1471-1474.

30. Gravenstein S, Drinka P, Osterweil D, Schilling M, Krause P, Elliott M, Shult $P$, Ambrozaitis A, Kandel R, Binder $E$, et al: Inhaled zanamivir versus rimantadine for the control of influenza in a highly vaccinated longterm care population. Journal of the American Medical Directors Association 2005, 6:359-366.

31. Hayden FG, Jennings $L$, Robson R, Schiff $G$, Jackson $H$, Rana $B$, McClelland G, Ipe D, Roberts N, Ward P: Oral oseltamivir in human experimental influenza B infection. Antiviral Therapy 2000, 5:205-213.

32. Hayden FG, Gubareva LV, Monto AS, Klein TC, Elliott MJ, Hammond JM, Sharp SJ, Ossi MJ: Inhaled zanamivir for the prevention of influenza in families. New England Journal of Medicine 2000, 343:1282-1289.

33. Hayden FG, Belshe R, Villanueva C, Lanno R, Hughes C, Small I, Dutkowski R, Ward P, Carr J: Management of influenza in households: a prospective, randomized comparison of oseltamivir treatment with or without postexposure prophylaxis. Journal of Infectious Diseases 2004, 189:440-449.

34. Hedrick JA, Barzilai A, Behre U, Henderson FW, Hammond J, Reilly L, Keene $O$ : Zanamivir for treatment of symptomatic influenza $A$ and $B$ infection in children five to twelve years of age: a randomized controlled trial. Pediatric Infectious Disease Journal 2000, 19:410-417.

35. Ison MG, Szakaly P, Shapira MY, Krivn G, Nist A, Dutkowski R: American Journal of Transplantation Conference: American Transplant Congress 2009 Boston, MA United States Conference Start: 20090530 Conference End: 20090603 Conference: American Transplant Congress 2009 Boston, MA United States Conference Start: 200. 2009, 240:331.

36. Whitley RJ, Hayden F, Reisinger KS, Young N, Dutkowski R, Ipe D, Mills R, Ward P: Oral oseltamivir treatment of influenza in children. Pediatric Infectious Disease Journal 2001, 20:127-133.

37. Cost C, Brock E, Siegel JD, Ardura M: Pediatric Blood and Cancer Conference: 23rd Annual Meeting of the American Society of Pediatric Hematology/Oncology, ASPHO 2010 Montreal, QC Canada Conference Start: 20100407 Conference End: 20100410 Conference: 23rd Annual Meeting of the American Soci. 2010, 437:823.

38. Harvala $H$, Gunson $R$, Simmonds $P$, Hardie A, Bennett $S$, Scott F, Roddie H, McKnight J, Walsh T, Rowney $D$, et al: The emergence of oseltamivirresistant pandemic influenza $A(\mathrm{H} 1 \mathrm{~N} 1) 2009$ virus amongst hospitalised immunocompromised patients in Scotland, November-December, 2009. Euro Surveillance: Bulletin Europeen sur les Maladies Transmissibles = European Communicable Disease Bulletin 2010, 15.

39. Hatakeyama S, Sugaya N, Ito M, Yamazaki M, Ichikawa M, Kimura K, Kiso M, Shimizu H, Kawakami C, Koike K, et al: Emergence of influenza B viruses with reduced sensitivity to neuraminidase inhibitors. JAMA 2007, 297:1435-1442

40. Kawai N, Ikematsu H, Iwaki N, Kawashima T, Maeda T, Mitsuoka S, Kondou K, Satoh I, Miyachi K, Yamaga S, et al: Longer virus shedding in influenza $B$ than in influenza A among outpatients treated with oseltamivir. Journal of Infection 2007, 55:267-272.

41. Stephenson I, Democratis J, Lackenby A, McNally T, Smith J, Pareek M, Ellis J, Bermingham A, Nicholson K, Zambon M: Neuraminidase inhibitor resistance after oseltamivir treatment of acute influenza $A$ and $B$ in children. Clinical Infectious Diseases 2009, 48:389-396.

42. Tramontana AR, George B, Hurt AC, Doyle JS, Langan K, Reid AB, Harper JM Thursky K, Worth LJ, Dwyer DE, et al: Oseltamivir resistance in adult oncology and hematology patients infected with pandemic (H1N1) 2009 virus, Australia. Emerging Infectious Diseases 2010, 16:1068-1075.

43. Wang B, Dwyer DE, Blyth CC, Soedjono M, Shi H, Kesson A, Ratnamohan M, McPhie $K$, Cunningham AL, Saksena NK: Detection of the rapid emergence of the $\mathrm{H} 275 \mathrm{Y}$ mutation associated with oseltamivir resistance in severe pandemic influenza virus A/H1N1 09 infections. Antiviral Research 2010, 87:16-21.

44. Winzer R, Kanig N, Schneitler S, Reuter S, Jensen B, Muller-Stover I, Oh J, Adams O, Mayatepek E, Hengel $H$, et al: Early clinical experiences with the new influenza A (H1N1/09). Deutsches Arzteblatt International 2009, 106:770-776.

45. Buchholz U, Brockmann S, Duwe S, Schweiger B, an der HM, Reinhardt B, Buda S: Household transmissibility and other characteristics of seasonal oseltamivir-resistant influenza A(H1N1) viruses, Germany, 2007-8. Euro Surveillance: Bulletin Europeen sur les Maladies Transmissibles = European Communicable Disease Bulletin 2010, 15.

46. Ciancio BC, Meerhoff TJ, Kramarz P, Bonmarin I, Borgen K, Boucher CA Buchholz U, Buda S, Dijkstra F, Dudman S, et al: Oseltamivir-resistant influenza $\mathrm{A}(\mathrm{H} 1 \mathrm{~N} 1)$ viruses detected in Europe during season 2007-8 had epidemiologic and clinical characteristics similar to co-circulating susceptible $\mathrm{A}(\mathrm{H} 1 \mathrm{~N} 1)$ viruses. Euro Surveillance: Bulletin Europeen sur les Maladies Transmissibles = European Communicable Disease Bulletin 2009, 14.

47. Hauge SH, Dudman S, Borgen K, Lackenby A, Hungnes O: Oseltamivirresistant influenza viruses $A(\mathrm{H} 1 \mathrm{N1})$, Norway, 2007-08. Emerging Infectious Diseases 2009, 15(2):155-162, Date of Publication: February 2009 2009, 379 155-162.

48. Dharan NJ, Gubareva LV, Meyer JJ, Okomo-Adhiambo M, McClinton RC, Marshall SA, St GK, Epperson S, Brammer L, Klimov Al, et al: Infections with oseltamivir-resistant influenza $\mathrm{A}(\mathrm{H} 1 \mathrm{~N} 1)$ virus in the United States. JAMA 2009, 301:1034-1041

49. Baz M, Abed Y, Papenburg J, Bouhy X, Hamelin ME, Boivin G: Emergence of oseltamivir-resistant pandemic $\mathrm{H} 1 \mathrm{~N} 1$ virus during prophylaxis. $\mathrm{N}$ Engl J Med 2009, 361:2296-2297.

50. Baz M, Abed Y, McDonald J, Boivin G: Characterization of multidrugresistant influenza $\mathrm{A} / \mathrm{H} 3 \mathrm{~N} 2$ viruses shed during 1 year by an immunocompromised child. Clinical Infectious Diseases 2006, 43:1555-1561.

51. Le QM, Someya K, Sakati YT: Avian flu: Isolation of drug-resistant H5N1 virus. Nature 2005, 478.

52. de Jong MD, Tran TT, Truong HK, Vo MH, Smith GJ, Nguyen VC, Bach VC, Phan TQ, Do QH, Guan Y, et al: Oseltamivir resistance during treatment of influenza A (H5N1) infection. New England Journal of Medicine 2005, 353:2667-2672

53. Campanini G, Piralla A, Rovida F, Puzelli S, Facchini M, Locatelli F, Minoli L Percivalle E, Donatelli I, Baldanti F, et al: First case in Italy of acquired resistance to oseltamivir in an immunocompromised patient with influenza A/H1N1v infection. Journal of Clinical Virology 2010, 48:220-222.

54. Cane A, Casanueva E, lolster T, Sticco N, Richards L, Sosa P, Pontoriero A, Avaro M, Zcech A, Carabajal E, et al: First isolation of a oseltamivirresistant influenza $A(\mathrm{H} 1 \mathrm{~N} 1)$ strain in Argentina. Pediatric Infectious Disease Journal 2010, 29:384.

55. Centers for Disease Control and Prevention (CDC): Oseltamivir-resistant novel influenza $A(\mathrm{H} 1 \mathrm{~N} 1)$ virus infection in two immunosuppressed patients - Seattle, Washington, 2009. MMWR - Morbidity \& Mortality Weekly Report 2009, 58:893-896.

56. Centers for Disease Control and Prevention (CDC): Oseltamivir-resistant 2009 pandemic influenza A (H1N1) virus infection in two summer campers receiving prophylaxis-North Carolina, 2009. MMWR - Morbidity \& Mortality Weekly Report 2009, 58:969-972.

57. Couturier BA, Bender JM, Schwarz MA, Pavia AT, Hanson KE, She RC: Oseltamivir-resistant influenza A 2009 H1N1 virus in immunocompromised patients. Influenza and other Respiratory Viruses 2010, 465:199-204, 4 (4) (pp 199-204), 2010 Date of Publication: July 2010.

58. Dulek DE, Williams JV, Creech CB, Schulert AK, Frangoul HA, Domm J, Denison MR, Chappell JD: Use of intravenous zanamivir after development of oseltamivir resistance in a critically III immunosuppressed child infected with 2009 pandemic influenza A (H1N1) virus. Clinical Infectious Diseases 2010, 50:1493-1496.

59. Gaur AH, Bagga B, Barman S, Hayden R, Lamptey A, Hoffman JM, Bhojwani D, Flynn PM, Tuomanen E, Webby R: Intravenous zanamivir for oseltamivir-resistant $2009 \mathrm{H} 1 \mathrm{~N} 1$ influenza. New England Journal of Medicine 2010, 362:88-89.

60. Glikman D, Zonis Z, Hindiyeh M, Ram D, Mandelboim M, Mendelson E, Engelhard D: Development of oseltamivir resistance during oseltamivir therapy in a child with severe $2009 \mathrm{H} 1 \mathrm{~N} 1$ influenza. [Erratum appears in Pediatr Infect Dis J. 2010 May;29(5):478 Note: Hindyieh, Musa [corrected to Hindiyeh, Musa]]. Pediatric Infectious Disease Journal 2010, 29:385-386. 
61. Hill-Cawthorne GA, Schelenz S, Lawes M, Dervisevic S: Oseltamivir-resistant pandemic (H1N1) 2009 in patient with impaired immune system. Emerging Infectious Diseases 2010, 16:1185-1186.

62. Ison MG, Gubareva LV, Atmar RL, Treanor J, Hayden FG: Recovery of drugresistant influenza virus from immunocompromised patients: a case series. [Review] [16 refs]. Journal of Infectious Diseases 2006, 193:760-764.

63. Memoli MJ, Hrabal RJ, Hassantoufighi A, Jagger BW, Sheng ZM, Eichelberger MC, Taubenberger JK: Rapid selection of a transmissible multidrug-resistant influenza $\mathrm{A} / \mathrm{H} 3 \mathrm{~N} 2$ virus in an immunocompromised host. Journal of Infectious Diseases 2010, 201:1397-1403.

64. Nguyen HT, Fry AM, Loveless PA, Klimov Al, Gubareva LV: Recovery of a Multidrug-Resistant Strain of Pandemic Influenza A 2009 (H1N1) Virus Carrying a Dual H275Y/I223R Mutation from a Child after Prolonged Treatment with Oseltamivir. CID 2010, 51:983-984.

65. Rousset D, Goff JL, Abou-Jaoude G, Molina JM, Scelma A, Caro V, Enouf V, Simon $\mathrm{F}$, van der Werf S: Emergence of successive mutations in neuraminidase of the pandemic $\mathrm{H} 1 \mathrm{~N} 1$ virus respectively associated with oseltamivir resistance and reduced susceptibility to both oseltamivir and zanamivir under treatment with neuraminidase inhibitors [abstract $\mathrm{P}$ 198]. Program and abstracts of the International Society forln?uenza and other Respiratory Virus Diseases Hong Kong SAR, China: Options forthe Control of Infuenza VII 2010.

66. Speers DJ, Williams SH, Pinder M, Moody HR, Hurt AC, Smith DW: Oseltamivir-resistant pandemic (H1N1) 2009 influenza in a severely ill patient: the first Australian case. Medical Journal of Australia 2010, 192:166-168.

67. Thabet AA, Al-Bahlooli SH, Al-Kohlani A, Shoja'a A: Oseltamivir-resistant pandemic (H1N1)2009 in Yemen - case report. Virology Journal 2010, 7:88.

68. van der Vries E, Stelma FF, Boucher CAB: Emergence of MultidrugResistant Pandemic Influenza A (H1N1) Virus. New England Journal of Medicine 2010, 363:1381-1382.

69. Hamelin ME, Baz M, Abed Y, Couture C, Joubert P, Beaulieu E, Bellerose N, Plante M, Mallett C, Schumer G, et al: Oseltamivir-resistant pandemic A/ $\mathrm{H} 1 \mathrm{~N} 1$ virus is as virulent as its wild-type counterpart in mice and ferrets. PLoS Pathog 2010, 6:e1001015.

70. Kohno S, Kida H, Mizuguchi M, Shimada J: Efficacy and safety of intravenous peramivir for treatment of seasonal influenza virus infection. Antimicrob Agents Chemother 2010, 54:4568-4574.

71. Boltz A, Douangngeun B, Phommachanh P, et al: Emergence of H5N1 avian influenza viruses with reduced sensitivity to neuraminidase inhibitors and novel reassortants in Lao People's Democratic Republic. Journal of General Virology 2010, 91:949-959.

72. Earhart KC, Elsayed NM, Saad MD, Gubareva LV, Nayel A, Deyde VM, Abdelsattar A, Abdelghani AS, Boynton BR, Mansour MM, et al: Oseltamivir resistant mutation N249S in human influenza (H5N1) virus in Egypt. Journal of infection and public health 2009, 2:74-80.

\section{Pre-publication history}

The pre-publication history for this paper can be accessed here: http://www.biomedcentral.com/1471-2334/11/134/prepub

\section{doi:10.1186/1471-2334-11-134}

Cite this article as: Thorlund et al: Systematic review of influenza resistance to the neuraminidase inhibitors. BMC Infectious Diseases 2011 11:134.

\section{Submit your next manuscript to BioMed Central and take full advantage of:}

- Convenient online submission

- Thorough peer review

- No space constraints or color figure charges

- Immediate publication on acceptance

- Inclusion in PubMed, CAS, Scopus and Google Scholar

- Research which is freely available for redistribution 